\title{
Assessment And Intervention Using The Perspective Of Four Organizational Frames
}

\author{
Dean Grace, Northwood Children's Home \\ Rebecca Korach, Park Nicollet Clinic \\ Kim Riordan, (E-mail: kriordan@d.umn.edu), University of Minnesota Duluth \\ Kim Storm, Duluth YWCA
}

\begin{abstract}
Effective leaders must possess a sophisticated understanding of their multifaceted organizations. This includes an understanding of the organization from several perspectives. The purpose of this paper is to explore the use of reframing, the perspective that organizations can be viewed from more than one angle (Bolman \& Deal, 2003). Included in this paper are descriptions of the four perspectives along with short case studies intended to illustrate the four frames from the standpoint of assessment and intervention. This paper is intended as a resource to persons responsible for leadership at the middle level ranks in their respective organizations. Prior to reading this paper the authors suggest you complete and score the survey (see Appendix A for survey).
\end{abstract}

\section{INTRODUCTION}

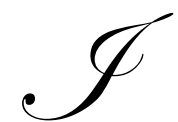

$\mathrm{n}$ a world of increasing complexity, effective leaders must strive to understand their multifaceted organizations. This includes understanding organizations from several perspectives. These perspectives include an appreciation of the extraordinary influence of human dynamics, and the importance of using structures within the organization to promote the vision and mission of the organization. Further, a multi-perspective view of organizations includes an awareness of the importance of enhancing culture within work environments. Not insignificant, is an understanding of the artful use of politics to increase our influence.

Covey (1990) suggests we seek first to understand and then to be understood. Unfortunately, on an organizational level we often misunderstand and misdiagnose. We misinterpret a coworker's message or we misread the intent behind a memo or email. We follow our assumptions down a path of erroneous assessment of an issue or conflict. We deny the value of coalition building for fear we'll be seen as too political. In our attempt to make sense of issues we often are "clueless" to what may really be happening (Bolman and Deal, 2003). This sensemaking that occurs in organizations is inherent to our social make-up. Our desire to make sense of the issues, problems, and questions of our times challenges us to stretch the way we see the world, and how we interpret the values, attitudes and motivations of those around us.

The need is greater than ever to accurately assess and appropriately intervene in organizational challenges. The challenge begins with reflection on past crises and the interventions we conducted. It may include recognition of why our past efforts failed, or an examination of how we lost our way in an attempt to remedy a situation.

The purpose of this paper is to explore the use of reframing, the perspective that organizations can be viewed from more than one angle (Bolman and Deal, 2003). Included in this paper are descriptions of the four perspectives along with short case studies intended to illustrate the four frames from the standpoint of assessment and intervention.

It is possible to view organizations from a perspective that acknowledges their complexity. This includes an acceptance of the inherent conflict, power and structural issues that are intrinsically woven into the fabric of our organizational settings. Along with this, is the necessary recognition that our groups or work teams operate out of needs, goals, and desires that may be counter to the larger organizational goals. To ignore the human dynamics, which are in constant interplay with our organizational goals, is to deny the reality of the power of relationship. Bolman and 
Deal (2003) view organizations through four frames. These are described as factories (structural frame), families (human resource frame), jungle (political frame) and theaters (symbolic frame). It is their belief that leaders who are able to view their organizations from multiple frames are the leaders who will effectively manage the conflict they encounter. A summary of the assumptions that underlie each of these organizational frames can be found in Appendix B.

The four distinct frames outlined by Bolman and Deal (2003) suggests that when we view organizational issues through different lenses, we increase the likelihood that we can recognize, and more effectively respond to, management and organizational challenges with flexibility, creativity, and compassion. This belief with the expanded view that there is no one "right" perspective with which to view those challenges allows leaders to see and respond to a wider range of possibilities.

Following are four case examples. The scenarios are focused on human service and educational programs, but they readily apply to a variety of organizations. Part one describes a problem or dilemma, often faced by middle level managers. Part two describes how a particular frame may add to the leader's understanding of the underlying issues involved in the problem scenario. Part three introduces an example of an effective intervention strategy (structural, human relations, political or symbolic) suggested by the leader's assessment of the problem. At the end of the paper the reader will find a matrix of assessment criteria and corresponding team building or broader organizational development interventions (see Appendix $\mathrm{C}$ for matrix).

\section{THE STRUCTURAL FRAME}

\section{Background}

Sue reflected on her first six weeks as a new supervisor for an in-patient adolescent treatment program. She had taken over a team with a reputation for good performance. The previous supervisor had accepted a promotion. Several other members had left the agency at the same time. Sue had been able to participate in the hiring decisions for their replacements. While she was happy with the new hires, she knew she was short on experience. Nevertheless, when she accepted the promotion she was excited about working with the members of her new team. She knew most of them and thought of them as motivated and capable people. Because they seemed supportive of her promotion she did not anticipate what she was experiencing now. They all seem willing enough to respond to her direction. However, a month had passed and she was feeling increasingly overwhelmed by all the responsibilities and details she had to manage. She expected members to step up and shoulder a greater portion of the workload. When they did not she became increasingly disappointed with their performance. Sue began to question her initial optimistic assessment.

At the advice of her supervisor, Sue sat down with each of her team members individually and asked a series of questions to understand their perspective of the team's functioning. When she asked her staff to describe the team's mission only her two most senior staff really understood what she was asking. When she asked member to describe their role and job functions they could only provide vague answers. Everyone agreed that while follow through on her directions was generally good, follow through on team decisions was generally short-lived and inconsistent. This was especially an issue for Sue when it resulted in inconsistent treatment interventions by her staff with the students in their care. Despite the apparent capabilities of her team members, simple, routine, but important things like outcome charting got missed almost daily. Members reported there was a lot of complaining about things not getting done, but acknowledged there was way too little initiative to get them done. Too often the perception was that it was someone else's job. A couple of her staff seemed to feel more responsible than others to fill the gaps and she thanked them repeatedly for their help. However, although no one raised the issue in her interviews, she was hearing second hand there were grumblings about her leadership. The complaints revolved around two themes. One criticism was that she was not holding some members accountable for the same things expected of those few who did step up. The other complaint, usually attributed to newer staff, was that she was critical of staff without first clearly stating what she expected. 


\section{Assessment}

Sue's agency, like most human service organizations, has a strong orientation to teamwork. Many of these organizations structure their programs and services around teams. According to Katzenbach and Smith (1993) teams differ from work groups in a number of important ways. Teams are built around common goals and objectives. The structure of the team reflects its goals. Commitment to goals is reflected through on-going assessment of, and response to, outcome measures. Teams are manageable in size, generally between 10 and 25 members, and include members with requisite, diverse attributes, and skill sets. Teams are committed to building effective working relationships and holding each other collectively accountable for results. Bolman and Deal (2003) point out that teams take on different forms and need different leadership depending on the tasks facing them at the time. Hersey (1984) also notes that team members need different styles of leadership at different developmental stages.

There is, according to Bolman and Deal (2003), no one best way to organize and structure a team or an organization. The structure depends on many factors, including the size of the organization, the mission or purpose, the core processes used by the organization in pursuit of its mission, the technology available to the organization, the skills and competencies of its members, the ability or inability of leadership to guide and direct all aspects of operations, and the environment in which it works. Human services organizations, for example, operate in a highly regulated environment which impacts the leaderships need to control critical aspects of the operation such as risk management. At the same time, 24 hour operations like Sue's in-patient treatment program are practically compelled to provide staff with some degree of autonomy and flexibility to make decision in the absence of the immediate supervisor. Striking the proper balance between tight controls and flexible structures is critical. This balance must be reflected in the understanding line staff have of their roles and responsibilities. They must clearly understand what responsibilities have been assigned to them (differentiation), but they must also understand how they fit into and are responsible to the larger organization (integration). The failure of the lowliest employee to understand his or her role and responsibilities will at minimum cause headaches for his or her supervisor. The potential exists for that person's actions, whether by commission or omission, to bring down the organization. Leaders often fail to recognize how critical and complex decisions about team structure can be.

Sue had begun to do what happens repeatedly in organizations. She began to label new staff that was unclear about their role and responsibilities as unmotivated or under performers. Experienced, responsible staff became complainers when they expected things to work as well with new leadership and new staff as they had months before on a veteran team with clear lines of communication and well-practiced procedures. In Sue's case, her team members really had the potential she saw when she accepted the opportunity to lead them. They just needed to understand how to show her. When leaders are confronted with a lack of clarity about goals, responsibilities or accountabilities, the issue and the solution is often structural in nature.

\section{Intervention}

Sue's team was unclear about its mission and goals and members did not understand who was responsible for what. As this situation continued it inevitably led to conflicts between members. Members actually desired increased accountability but were defensive about comments that seemed to suggest their motivation was the issue.

When team performance is negatively impacted by structural problems a range of interventions may be useful. French and Bell (1999) identify a number of techniques that can be used in team building to facilitate improved team performance and address specific problems and these are:

1. Role analysis technique to clarify role expectations and obligations.

2. Interdependency exercises to improve cooperation among members.

3. Role negotiation to address behaviors that are resistant to change due to a concern over potential loss of power (see political frame for related interventions).

4. Appreciation and concern exercise to address a lack of appreciation or unspoken irritations between members (see human resource frame for more interventions). 
5. Responsibility charting clarifies who does what tasks, who is involved in a supporting role, and what are the reporting relationships. Responsibility charting clarifies the potential complexity and impact of even simple tasks.

6. Visioning involves group members agreeing to a description of what they would like their team or agency to look like anywhere between six months and five years into the future. Visioning can be a powerful tool to create shared meaning (see symbolic frame for more ideas).

7. Force-field analysis is one of the oldest interventions having been pioneered by Kurt Lewin in 1947. Forcefield analysis helps members understand both the structural and political nature of a problem and to plan corrective actions.

Generally, leaders should begin by assessing the clarity of mission and goals. If the basic purpose of the team is unclear to members or stakeholders, then there is little way to determine what structural change will help. Organizational or team structure is designed to support mission, to help enable members to achieve their collective purpose in the most effective and efficient manner possible.

In Sue's case, she began by meeting with her team to develop a mission statement and clearly defined goals to achieve that mission. Once the team was clear what needed to be done, they organized their effort by deciding who would do what. Sue chose to use a role clarification exercise to help the team effectively assign tasks, roles, accountability, and leadership. Roles included responsibility for important team tasks, as well as contributing to effective team processes.

As noted earlier, in many human service organizations staff works much of the time outside direct supervision. Instead of the traditional boss-employee relationship, much of the accountability in these organizations is to team members. Consequently, as teams develop, members are typically granted more autonomy and flexibility. The trade-off is that members assume more ownership for team performance. As Sue's team develops she will need to revisit the role clarification process to account for greater levels of shared leadership within the team structure.

\section{THE HUMAN RESOURCE FRAME}

\section{Background}

Jeri Tanner was transferred from Arizona to Northern Minnesota to become the executive director of a regional mental health center with over 100 employees. Her first impression of this new assignment was that the staff demonstrated poor morale. A significant emotional distance was observed between the administration and the general staff. During the first agency meeting, Jeri attempted to engage staff in a warm-up exercise for groups. Several employees refused to participate or provide input into the process. Instead, they remained silent, as if they were attending a lecture. There appeared to be a sense of distrust exhibited by the employees towards administration. Jeri had an educational background in psychology and was vigilant about the energy level and tone of the workplace environment. The cynical attitude of employees, defensive posturing, and the rate of job turnover reflected the deep detachment of many individuals who chose to work in the organization. Jeri was concerned that this "detachment" would ultimately sabotage the goal of the agency in creating a nurturing environment to help clients emotionally.

As the regional administrator, Jeri had been transferred to integrate new protocol and technology that prior directors had been unsuccessful in implementing. Her task was to make these changes in a short period of time. She assumed employees would be excited about changes in the work environment, which could make their jobs more efficient. Since she had always been direct and open in her communication, she announced upcoming technological changes for the agency. Her staff responded with anxiety and resistance when she shared her ideas of how the implementation process would take place. Many complained that they felt inadequate in utilizing the current technology. Jeri Tanner was faced with an increasingly hostile environment with her employees. 


\section{Assessment}

The human resource frame is ideal for assessing Jeri's present circumstances in filling her role as executive director. A person given the role of leader in an agency, which has neglected the employee, will be most effective by implementing the theory of "empowerment". French and Bell (1999) define the empowerment process with the organization as "those leadership behaviors and human resource practices that enable organizational members to develop and use their talents as fully as possible toward individual growth and organizational success" (p.26). According to Bolman and Deal (2003), the human resource leader demonstrates support of the individual and works to facilitate participation and open communication. Leaders who utilize the theory of empowerment, assist their employees in becoming self-actualized by providing the employee the opportunity to learn, develop ownership, and feel a part of the success of their company.

When employees demonstrate poor morale and a low level of commitment to the organization, there is often an absence of the human resource frame used by management in the organization. Workers who feel disengaged and sense they have limited power in an organization develop defensive routines of cynicism, mistrust, and resist change (Argyrols \& Schon 1996). When individual commitment is identified as low, and employees feel helpless and unacknowledged, the human resource frame may be the best frame to provide intervention.

Once an organization determines that the Human Resource Frame would be useful in addressing a problem in the organization, a variety of intervention strategies may be helpful. Cameron \& Quinn (1999) suggest several ways to energize employees including: reward and incentive programs, celebrations, workplace mentors, keeping the workplace a positive and affirming environment, and asking for input. An initial intervention a manager or supervisor can implement from the human resource perspective would be to create an opportunity for people to share their concerns, ideas, and feelings. Staff meetings can open with the opportunity for people to spend five minutes sharing their ideas and accomplishments. Special feedback boxes and evaluation forms for employees can provide the opportunity to bring up issues they would not normally verbalize in meetings. Small groups can be designed to generate team spirit and new ideas for business growth or productivity.

Appreciative inquiry (Ai) is a novel approach of intervention in the field of organizational development consistent with the human resource frame. Cooperrider (1996) describes the four phases of the Ai process as:

1. Discovery of people's experiences of their group, organization, or community at its most vital and alive and what made those experiences possible.

2. Dreaming together to envision a future in which those exceptional experiences form the bases for organizing.

3. Designing appreciative systems and structure to support the manifestation of co-created dreams.

4. Destiny or delivery, which involves implementation of those systems and structures in an ever-expanding positive -feedback loop of appreciative learning"(as cited in French, Bell, \& Zwacki, 2005, p.226).

As Jeri Tanner assessed her current situation, she identified several organizational development interventions to address the problems she had observed during her initial meeting with her employees. Her strategy of intervention was based from a human resource frame of leadership.

\section{Intervention}

Jeri Tanner began to implement interventions to assist her relationship with her staff and create a more positive environment. She established an open door policy in her office. She would greet each staff as they arrived, created continental breakfasts at early morning meetings, and began the task of getting to know her employees beyond their job titles.

Tanner held small group meetings to engage employees and encourage participation. She referred to these groups as "Appreciative Inquiry Groups" and explored with employees' positive experiences, their visions of a supportive environment, ideas for promoting a positive work environment, and how to develop a mechanism for ongoing feedback for management. 
Input from employees was solicited through weekly meetings, daily interactions and monthly surveys. A feedback box was placed in the lobby for both staff and clients to share their input. Tanner did not view herself as the "boss"; she described herself as part of the team, and would strive to personally affirm each employee's contribution to the mental health center. She was frequently found assisting employees on work related tasks. A bulletin board was used at the entrance of the mental health center to highlight the employee of the week. Birthdays, employee celebrations, and potluck gatherings were highlighted on a monthly schedule. Soon, employees were talking with more enthusiasm and interest in the agency. Weekly meetings opened with "celebrations" in which employees would share accomplishments and pleasurable moments at work and home. Tanner enjoyed the sense of family atmosphere emerging as people became more invested in their relationships at work. A sense of ownership was developed as people verbalized their goals for the agency through appreciative inquiry groups.

Communication was open and direct. Jeri Tanner empowered her employees to voice their concerns in staff and board meetings. She always began her meetings with gratitude for the employees who were the heart of the agency. Her strategy of keeping the employees the center of organization provided an ideal opportunity to transform her agency through a human resource frame of leadership.

\section{THE POLITICAL FRAME}

\section{Background}

The first thing Barry noticed when he walked into work was his new title above the nameplate, "Director of Operations." It tripped off his tongue easy, as though he'd been waiting to hear it for years. Actually, he had been waiting to hear it for years. Years of working his way up, playing the game, kissing a lot of...well, he'd finally arrived and he was done playing the game. He was in charge now. "At last," he thought to himself, "the opportunity to make some real changes around here." The first order of the day was to check in with the shift supervisors and personnel manager. Because of a decision to change shift patterns, a number of staff were getting demanding. They didn't like the new start times, they perceived they were getting less weekend time off, and they felt they had no control over their schedules. The union had been called and Barry knew that if he didn't play this right, there could be big trouble. So far, he'd avoided having to let the board of directors know about the trouble that was brewing.

Where do we start, folks? he asked from behind his desk, as the group of supervisors sat assembled in his office. There were a number of suggestions made, We should meet with the union and head off any problems, suggested the personnel manager. We've worked with the reps before and they've genuinely seemed to want to work with us. Another offered, It's probably not too late to revisit the scheduling changes, look at what has people most concerned. Some of the folks, who have years of seniority, make a strong point. And another, Let's round up some folks who are willing to talk frankly about this and get to the bottom of it. We can promise them confidentiality.

Barry's thoughts turned to the board of directors. They had, after all, trusted him to oversee the operations of the organization. They trusted him to make the right decision. He felt resentful toward the employees. Why couldn't people just do their job? Didn't they know he had bigger fish to fry? "I'll tell you what we're going to do. Nothing." There was silence in the room. "I'm sick of the bellyaching. If they don't like it, let them walk. And as far as the union? Those idiots have nothing better to do than to stir up trouble for me." An uncomfortable cough hung heavily in the office. "Barry? Don't you think we should involve some of the employees who are most affected by the changes?" offered Moira, the newest member of the team, a young woman who was responsible for the late afternoon shift. "I don't think we can afford to alienate the people on the front line. I really don't think they want to make trouble; they just want to be heard. It wasn't that long ago that I was working front line with them and I think they have some valid ..." Barry interrupted her, "Maybe you want to be back on the front-line? Are you with us, or against us? You're management now; remember whose side you're playing on!"

In the days that followed Barry received a call from the union rep asking for a meeting in the coming week. The rep asked for a representative from the board of directors to attend as well. Barry declined to meet with the rep until it was convenient for him, a week from tomorrow. He also neglected to inform the board chairperson, and figured he'd simply tell the union rep that no one was available on the particular day that was scheduled. 
As the meeting date approached, Barry continued to hear grumbling. As response, he had sent out a memo that work issues and concerns were no longer to be discussed during work time. Instead, employees could discuss issues about work in their off time. Further, he had given Moira, the newest member of the management team, a letter to sign. It was a letter that outlined her insubordination, from the day of the meeting in his office; a letter that would be placed in her personnel file...

\section{Assessment}

Within the framework of Bolman and Deal's (2003) theory of reframing organizations is the political frame. The political frame is fraught with misunderstanding and negative connotations. When we hear the word political, we likely conjure images of power hungry autocrats, or backroom deals. What if, instead of the negative connotations we so readily ascribe to all that is political, we recognized organizational politics for what they are? Bolman and Deal (2003) believe "Politics is simply the realistic process of making decisions and allocating resources in a context of scarcity and divergent interests" (p. 181). They further suggest that politics are a necessary ingredient to organizational effectiveness.

It is not the politics that should be avoided. In fact, it is unlikely that politics could even be removed within any system. It is, however, critical that organizational leaders understand and recognize the dynamics of politics within their organizations.

Bolman and Deal (2003) suggest a number of assumptions that differentiate the political frame from the other three frames (structure, human resources and symbolic). These assumptions are:

1. "Organizations are coalitions of diverse individuals and interest groups.

2. There are enduring differences among coalition members in values, beliefs, information, interests, and perceptions of reality.

3. Most important decisions involve allocating scarce resources-who gets what.

4. Scarce resources and enduring differences make conflict central to organizational dynamics and underline power as the most important asset.

5. Goals and decisions emerge from bargaining, negotiation, and jockeying for position among competing stakeholders" (p. 186).

A further concept of the political frame is that of power. Power is an inevitable ingredient in political activity. It is a part of the ongoing negotiation and collaboration that exists within systems. While there is no doubt that power can be abused within organizational settings, it can also be viewed as the leverage necessary to persuade, influence and build capacity.

Within the conceptual view of power as a component of the political frame, it is important to recognize there are a variety of sources of power and these include: (1) position power, (2) information and expertise power, (3) control of rewards power, (4) coercive power, and (5) personal power (p. 194-195). Position power is typified by those positions whereby individuals have been given power, such as formally sanctioned authority over others. For example a professor, or a corrections officer, manager or director, are persons with position power. Information and expertise power is characterized by individuals who have specific knowledge or extraordinary abilities, such as a specialist in a technology firm, or a prolific writer, or musician. Control of rewards power is demonstrated by the ability to lend support, whether politically, financially or through other connections, to affect the outcome of organizational objectives. Coercive power is exemplified in an individual's (or an entire group's) ability to use their clout or connections to obstruct or redirect the course of events in a way that does not take into account the needs or desires of all parties. Personal power comes from within. Charisma is often a characteristic of someone with personal power. Individuals who are able to generate followership, in part through their ability to articulate a vision, epitomize personal power. 


\section{Intervention}

It is unrealistic to believe that one's political position can be operationalized without the use of power, at least to some degree. This supports the belief that those in leadership positions wield power, whether they acknowledge it or not, and whether they think they use it, or not. The effective leader, according to Bolman and Deal (2003) uses his/her power to create an "agenda for change" (p. 205). In much the same way that an effective leader would conduct a stakeholder analysis at each critical juncture within an organization's development, so too, would the leader recognize the worth of examining the interrelationships and interdependencies inherent within their organization. By completing this assessment, the leader's political acumen is honed; by both recognizing the competing interests and balancing the needs of critical players.

It is precisely those political issues that Barry, the new Director of Operations, finds himself struggling with. In his new position, one of position power, Barry is using his position to intimidate and coerce others. While he may think he has legitimate power to make decisions, he's not using his power to be diplomatic and to support a win-win outcome. Instead, he bullies, humiliates, and generally ostracizes the people he most needs to have support from. He is not being political in a way that would acknowledge the needs of his constituents and afford them the opportunity to participate in problem solving.

Bolman and Deal (2003) describe the art of political acumen in their principles for political leaders and these are: (a) political leaders clarify what they want and what they can get; (b) political leaders assess the distribution of power and interest; (c) political leaders build linkage to key stakeholders; and (d) political leaders persuade first, negotiate second, and coerce only if necessary (p. 357). Barry would have done well to follow these principles.

\section{THE SYMBOLIC FRAME}

\section{Background}

All organizations have some degree of symbolic life. Bolman and Deal (2003) refer to this as an organization's cultural tapestry, and state:

The symbolic frame, drawing on social and cultural anthropology, treats organizations as tribes, theaters, or carnivals. It abandons assumptions of rationality more prominent in other frames. It sees organizations as cultures, propelled more by rituals, ceremonies, stories, heroes, and myths than by rules, policies, and managerial authority. Organization is also theater: actors play their roles in the organizational drama while audiences form impressions from what is seen onstage. Problems arise when actors blow their parts, when symbols lose their meaning, or when ceremonies and rituals lose their potency. (p. 15)

The recent acquisition of Shoreline Medical Center by Riverside Healthcare Systems illustrates the importance of symbols within an organization's culture, while also demonstrating that chaos can result when an organization's symbolic life is oppressed.

Shoreline Medical Center, a small Midwestern hospital, had been in business for decades, and was renowned in the community for its exceptional care, strong organizational culture, and employee pride. Shoreline Medical Center celebrated success regularly, through traditions such as annual employee picnics and awards banquets, employee appreciation celebrations, and holiday teas. It was not uncommon for departments to sponsor fundraising activities whether it was on behalf of an employee in need, or for a community cause such as cancer or heart disease. An employee-organized craft sale was held annually, with participants generously donating $10 \%$ of sales to the Shoreline Medical Center employee emergency fund.

Stories were part of everyday business at Shoreline Medical Center. New employees became quickly acquainted with the medical center lore. There were tales of the Chief Executive Officer, making a personal visit to an employee's critically ill child, and stories of administrative staff giving rides to employees on storm days. It was well known that many of the managers rolled up their sleeves and pitched in to help in times of need. 
The medical center's logo was significant and important to everyone who worked at Shoreline Medical Center, and its unpretentious, yet professional design was a perfect symbol of Shoreline's culture. Patients, visitors and employees alike were enveloped by this special culture.

Like many other small medical centers in the United States, Shoreline Medical Center began to experience financial struggles, in the late 1990's. It soon became apparent that in order to survive, Shoreline Medical Center would need to join a much larger healthcare system. The obvious choice was Riverside Healthcare Systems - a nearby healthcare system that came complete with more resources and deeper pockets.

Despite its strong financial status, it was no secret that Riverside Healthcare Systems had an image problem in the community. In terms of customer service, organizational symbolism, and employee culture, it stood in stark contrast to the warm cultural climate at Shoreline Medical Center. Throughout the acquisition, senior administrators acknowledged the strong cultural differences between the two medical centers. Riverside Healthcare Systems leaders coveted Shoreline's strong employee culture and desired to spread that culture across the parent organization.

Instead, within months of the acquisition the sacred culture at Shoreline Medical Center began to unravel. Employees at both medical centers were warned of potential layoffs, yet the majority of the layoffs occurred at Shoreline Medical Center. The layoffs included several Shoreline employees who were viewed as pillars in the organization. Their departure left a gaping hole in the heart of Shoreline's culture. It was too much, too soon, and Shoreline employees were clearly devastated by the loss.

Riverside Medical Center quickly imposed its policies and rules on Shoreline Medical Center. Employee fundraisers were halted and the annual craft sale was barred from happening. Shoreline was no longer allowed to have its own Christmas tea, awards banquet, and employee picnic. Rather, it was decided that employees would join Riverside's schedule of annual celebrations.

The crowning disappointment was when Shoreline Medical Center's logo was phased out and replaced by the logo of the parent company. Shoreline had officially lost its identity.

\section{Assessment}

While Riverside Health Systems was attentive to political issues, organizational structure, and human resources during its acquisition of Shoreline, it seriously failed to assess the rich symbolic life existing within the walls of Shoreline Medical Center.

There was obvious disconnect between what Riverside Health Systems said about the culture at Shoreline Medical Center, and what they actually did. French and Bell (1999) state, “...one of the most important things to manage in organizations is the culture: the prevailing pattern of values, attitudes, beliefs, assumptions, expectations, activities, interactions, norms, sentiments, and artifacts" (p. 27).

Although the pride, culture, and symbolism at Shoreline Medical Center was recognized as a good thing, Riverside Health Systems made no apparent efforts to keep the culture intact. Shortly after the acquisition, the cultural tapestry at Shoreline Medical Center was overturned, stripped away, and devalued. Employees were saddened and deeply distracted in their day-to-day work. The mood pervaded the community at large.

Wilt, Overbeck, and Fox (1998) state:

Whenever there is change, psychologists say, there is the perception of loss. Employees of merging hospitals grapple with the loss of identity that inevitably occurs when one of the institutions' cultures emerges as dominate. Still, change is a fact of life in today's healthcare environment, and healthcare leaders must be prepared to ease their employees through it. Ignoring the impact of change on workers, organizational change experts agree, can mean that they will brush off or even sabotage the organization's efforts to transform policy and practices. (p. 13) 
If Riverside Health Systems had assessed Shoreline Medical Center through the lens of the symbolic frame, much of the culture would be intact today. In this example, Riverside may have benefited from conducting an employee climate survey as well as a community climate survey.

The employee survey may have provided valuable insight about the specific symbols and rituals at Shoreline. It may have revealed what and who made up the culture, and might have brought to light, the depth of the pride permeating the organization.

Equally as important would have been a community survey, to learn the community's thoughts and feelings about the acquisition. Riverside Healthcare Systems failed to recognize that the customer provides valuable insight and should never be overlooked or underestimated. In this example, Shoreline Medical Center was well-known for its excellence, symbols, rituals, and stories, and indisputably had a strong following in the community.

Finally, leaders at Shoreline Medical Center could have been more assertive by assessing their individual departments during this time of rapid change. Had they done so, they might have found a means to retain some of the cultural richness, or might have uncovered new ideas for maintaining symbolism within the organization.

\section{Intervention}

Recognizing and understanding the value of symbolism in an organization is essential to any change process. Riverside Health Systems was well aware of the strong cultural and symbolic presence that Shoreline Medical Center possessed within the community, yet they failed to complete an assessment of the symbolic frame. While many would predict the demise of Shoreline's culture in the face of this blatant disregard, the culture at Shoreline did not disappear. The culture was rattled, but because it ran so deep, it was impossible to strip away.

As it turned out, the leaders that remained at Shoreline Medical Center were the ones who made the first attempts to intervene at preserving the rich culture, by starting within their own departments. Taking the place of the former hospital-wide fundraisers and celebrations, were similar events, held quietly within the confines of individual departments. No flyers or invitations were posted, in keeping with Riverside's policies, but nevertheless, news traveled quickly by word-of-mouth. Slowly but surely, the old traditions of Shoreline Medical Center were beginning to resurface.

It wasn't long until the parent company learned about the rebirth of the Shoreline spirit. Senior administrators realized they had underestimated both employee and community members' perceptions about the culture at Shoreline.

This realization led to Riverside Health System's decision to proceed with a symbolic assessment of the organization. The parent company conducted focus groups to assess the climate throughout the organization, and hired a marketing firm to conduct a community-wide survey, with a focus on where, why and how people choose their health care. The study results clearly showed that employees and the community, identified with Shoreline and its unique culture. Furthermore, they wanted the "old" Shoreline back.

Based on these findings, Riverside Health Systems realized it was time to intervene. Senior administrators adopted an entity-based management model, restoring much of Shoreline's former identity. Shoreline Medical Center was able to reclaim its original name and currently operates as its own entity, while still falling under the structure of the larger parent organization (Riverside Health Systems). Shoreline Medical Center was not able to reclaim its original logo, but as a compromise the logo retains an aspect of the old design, coupled with a color scheme shared with the parent organization.

Today at Shoreline Medical Center, the interventions continue. Many of them, including the resurrection of employee forums, celebrations, and fundraisers, are helping to restore the organizational culture. Annual measures of employee engagement and satisfaction confirm that Shoreline Medical Center is heading in the right direction. 


\section{SUMMARY}

"Leaders fail when they take too narrow a view" (Bolman and Deal, 2003, p. 433). It is our challenge as leaders to learn to view the world through a prism. A prism that allows us to see what is seemingly right in front of us, and at the same time view the many facets of that which we otherwise fail to take into account. The challenge is to examine these various views with flexibility. We begin to see our organizations through new frames of perspective. "Success requires artistry, skill, and the ability to see organizations as organic forms in which needs, roles, power, and symbols must be integrated to provide direction and shape behavior" (p. 433).

The reader is encouraged to view the skill of taking multiple perspectives as a process that requires time and experience. The authors encourage you to revisit the ideas contained in the accompanying matrix periodically to critique your personal and professional growth in this important leadership domain.

\section{Appendix A: Survey Instrument}

To score circle your response using the following scale:

4 - strongly agree, 3 - agree, 2 - disagree, 1 - strongly disagree

1. Clear goals and objectives are essential to any team's success.
4
3
2
1

2. Delegating and clarifying roles and responsibilities are critical tasks for leaders.
43
32
1

3. Team members need clearly defined processes and expectations to know how to work well with each other.
43
2
1

4. It is best to leave personality issues and personal situations out of work decisions.
43
2
1

5. Almost all performance problems can be corrected by changing how we do our work.
43
2
1

Total for items \#1-5:

6. People perform best when their needs are met by the organization.
4
3
2

7. Management should seek input from employees and value the unique talents of each employee.

$\begin{array}{llll}4 & 3 & 2 & 1\end{array}$

8. Employees feel more ownership when they are empowered to participate and provide input.

$\begin{array}{llll}4 & 3 & 2 & 1\end{array}$

9. When individuals find their work meaningful and satisfying a good "fit" exists between the employees and the organization.
$4 \quad 3$
32
1

10. It is important that the organizational environment is personal and caring.

$\begin{array}{llll}4 & 3 & 2 & 1\end{array}$

Total for items \#6-10: 
11. Most organizations are made up of coalitions of diverse individuals and interest groups.

$\begin{array}{llll}4 & 3 & 2 & 1\end{array}$

12. It is normal and healthy for there to be differences in values, beliefs and interests among members of the organization.
4
3
2
1

13. When it comes down to the hard decisions, it usually boils down to deciding on who gets what, in terms of resources.

$\begin{array}{llll}4 & 3 & 2 & 1\end{array}$

14. Conflict is central to organizational dynamics.
43
2
1

15. Most decisions are a result of bargaining and making concessions among the major players within the organization.
4
3
2
1

Total for items \#11-15:

16. The details of an incident are not as important as learning from the event and moving forward with a deeper understanding of the issue.
4
3
2
1

17. People interpret experiences differently; the strength of an organization lies in acknowledging and giving employees the freedom to do so.

$\begin{array}{llll}4 & 3 & 2 & 1\end{array}$

18. When an organization is experiencing turmoil, it is important to allow employees to embrace and carry on with longstanding traditions (logos, events, insignia, etc.).
$4 \quad 3$
2
1

19. There are many events or activities within an organization that add value to its culture, even when they don't necessarily contribute to the organization's level of productivity.
43
32
1

20. In order for a leader to be effective within an organization, he/she must acknowledge and integrate the value and beliefs of the employees.

$\begin{array}{llll}4 & 3 & 2 & 1\end{array}$

\section{Total for items \#16-20:}

Analysis: Compare your scores for items 1-5, structural frame, to items 6-10, human relations frame, items 11-15, political frame, and items 16-20, symbolic frame. What do these scores suggest about your tendency to lean toward or away from particular orientations in your efforts to understand what is happening on your team and in your organization?

High score ___ : Frame?

Low score _ : Frame?

Survey items based on Bolman and Deal (2003). 
$\underline{\text { Structural Assumptions }}$

\section{Appendix B: Assumptions}

1. Organizational exist to achieve established goals and objectives.

2. Organizations increase efficiency and enhance performance through specialization and a clear division of labor.

3. Appropriate forms of coordination and control ensure that diverse efforts of individuals and units mesh.

4. Organizations work best when rationality prevails over personal preferences and extraneous pressures.

5. Structures must be designed to fit an organization's circumstances (goals, technology, workforce, and environment).

6. Problems and performance gaps arise from structural deficiencies and can be remedied through analysis and restructuring.

\section{$\underline{\text { Human Resource }}$}

1. Organizations exist to serve human needs rather than the reverse.

2. People and organizations need each other. Organizations need ideas, energy, and talent. People need careers, salaries and opportunities.

3. When the fit between individual and system is poor, one or both suffer. Individuals are exploited or exploit the organization - or both become victims.

4. A good fit benefits both. Individuals find meaningful and satisfying work, and organizations get the talent and energy they need to succeed.

\section{Political}

1. Organizations are coalitions of diverse individuals and interest groups.

2. There are enduring differences among coalition members in values, beliefs, information, interests and perceptions of reality.

3. Most important decisions involve allocating scarce resources.

4. Scarce resources and enduring differences make conflict central to organizational dynamics and underline power as the most important asset.

5. Goals and decisions emerge from bargaining, negotiation, and jockeying for position among competing stakeholders.

\section{$\underline{\text { Symbolic }}$}

1. What is most important is not what happens but what it means.

2. Activity and meaning are loosely coupled; events have multiple meanings because people interpret experience differently.

3. In the face of widespread uncertainty and ambiguity, people create symbols to resolve confusion, increase predictability, find direction, and anchor hope and faith.

4. Many events and process are more important for what is expressed than what is produced. They form a cultural tapestry of secular myths, heroes and heroines, rituals, ceremonies, and stories that help people find purpose and passion in their personal and work lives.

5. Culture is the glue that holds an organization together and unites people around shared values and beliefs.

Based on Bolman and Deal (2003) 


\section{Appendix C Frames Matrix}

\section{Assessment}

\section{Intervention}

\section{Structural Frame}

Member concerns: confusion, loss of clarity and stability

- Unclear goals

- Lack of clarity about roles and responsibilities

- Uncertainty about accountabilities

- Lack of initiative and problem-solving behavior

- Lack of ownership, poor follow through

- Expecting too much/too little judgment from staff
Leader task: communicate, realign, and establish procedures

- (Re)define mission, vision, goals

- Role clarification

- Define accountability and authority for each job function

- Create more/less flexibility in structure

- Develop stronger team process

\section{Human Resource Frame}

Member concerns: anxiety, uncertainty, feeling incompetent

- Motivation problems

- Feelings of inadequacy

- Employees feel detached and isolated

- Employees are disengaged

- Poor morale
Leader task: train, support, encourage participation

- Create reward and incentive programs. Provide employee recognition.

- Provide employee skill training and workshops.

- Create social gatherings and celebrations.

- Create ownership through increased participation in decision-making, provide opportunities for input (surveys, evaluations and task groups).

- Affirm individual significance, utilize Appreciative Inquiry Groups.

\section{Political Frame}

Member concerns: conflict, disempowerment

- High level of conflict occurring on many levels within the organization.

- Considerable disagreement about how resources should be allocated.

- The goals of the organization seem uncertain

- Conflict with stakeholders

- Inter-departmental tensions
Leader task: create arenas for negotiation, form new coalitions

- Communicate the commonalties that different groups within the organization may have with one another

- Establish ways in which members of the organization can respectfully negotiate for what they need.

- Network

- Build coalitions

- Recognize and develop power bases

- Manage conflict 


\section{Symbolic Frame}

Member concerns: loss of meaning and purpose, clinging to past

- Lack of organizational or team pride

- Employees appear distracted by climate concerns

- Disconnect between what we say and what we do

- Employees unable to clearly articulate organizational values.
Leader task: create transition rituals, grieve past, celebrate future

- Conduct employee climate survey

- Celebrate achievements

- Develop new traditions and symbols

- Create organizational or team lore

- Focus on examples that reflect organizational values

- Survey stakeholder and consumer perceptions

Based on Bolman and Deal (2003)

\section{REFERENCES}

1. $\quad$ Argyris, C. and Schon, D. (1996). Organizational learning II. New York: Addison-Wesley.

2. Bolman, L. and Deal, T. (2003). Reframing organizations: Artistry, choice and leadership ( $3^{\text {rd }}$ ed). San Francisco: Jossey- Bass.

3. Cameron, K. and Quinn R. (1999). Diagnosing and changing organizational culture. New York: AddisonWesley.

4. $\quad$ Covey, S. (1990) The 7 habits of highly effective people: powerful lessons in personal change. New York: Fireside.

5. $\quad$ Goleman, D. (1998). Working with emotional intelligence. New York: Bantam Books.

6. French, W. (1999). Organizational development: Behavioral science interventions for organizational improvement. New Jersey : PrenticeHall.

7. French, W.L., Bell, C.H., and Zwacki, R.A. (2005). Organizational development and transformation: Managing effective change ( $6^{\text {th }}$ ed.). New York: McGraw-Hill Irwin.

8. French, W. and Bell, C. (1999). Organizational development: Behavioral science interventions for organizational improvement. New Jersey: PrenticeHall.

9. Hersey, P. (1984). The situational leader. New York: Warner.

10. Wilt, B., Overbeck, B., and Fox, R. (1998). Helping staff cope with change. The Quality Letter for Healthcare Leaders, 10(4), 13-17.

Copyright @ 2004 Dean Grace, Rebecca Korach, Kim Riordan and Kim Storm 
NOTES 